\title{
Falando sobre o "desconhecido": reflexões acerca de comentários homofóbicos produzidos numa postagem do Facebook sobre os estudos de gênero na Geografia.
}

\author{
Hablando sobre el "desconocido": reflexiones acerca de comentarios \\ homofóbicos producidos en un post de Facebook sobre los estudios de \\ género en la Geografía.
}
Talking about "unknown": reflections on homophobic comments produced in a Facebook post on gender studies in Geography.

\author{
Diego Miranda Nunes ${ }^{1}$
}

\begin{abstract}
Resumo
O estudo é resultado da análise de uma postagem e de seus comentários realizados no ciberespaço, na rede social Facebook, proferidos por uma figura pública de um partido político no município do Rio Grande - RS, acerca das discussões de gênero nas Ciências Humanas, em específico, na Geografia. Apresentamos uma reflexão sobre o "desconhecido", aferindo que no campo disciplinar da ciência geográfica, os estudos de gênero e sexualidades são discutidos a mais de 40 anos. A partir da análise da publicação, apontamos que a postagem e seus comentários são marcados por discursos homofóbicos e atravessados por olhares conservadores e de desconhecimento sobre o que a ciência geográfica estuda. Entendemos que os estudos de gênero na Geografia são potentes para uma visão ampliada do espaço geográfico, sabendo que este é produzido por sujeitos e seus marcadores sociais. Com isso, compreendemos que abordar os estudos de gênero e sexualidades em áreas tradicionais é dar visibilidade a grupos, historicamente marginalizados e, com isso, reduzir as desigualdades sócioespaciais.
\end{abstract}

Palavras-Chave: Conservadorismo; Gênero; Geografia; Homofobia; Redes sociais.

\section{Resumen}

El estudio es el resultado del análisis de un post y de sus comentarios realizados en el ciberespacio, en la red social Facebook, proferidos por una figura pública de un partido político en el municipio de Rio Grande - RS, acerca de las discusiones de género en las Ciencias Humanas, en específico en la Geografía. En el ámbito disciplinario de la ciencia geográfica, los estudios de género y sexualidad se discuten a más de 40 años. A partir del análisis de la publicación, señalamos que la entrada y sus comentarios están marcados por discursos homofóbicos y atravesados por miradas conservadoras y de desconocimiento sobre lo que la ciencia geográfica estudia. Entendemos que los estudios de género en la Geografía son potentes para una visión ampliada del espacio geográfico, sabiendo que éste es producido por sujetos y sus marcadores sociales. Con eso, comprendemos que abordar los estudios de género y sexualidades en áreas tradicionales es dar visibilidad a grupos, históricamente marginados y, con ello, reducir las desigualdades socioespaciales

Palabras claves: Conservatismo; Género; Geografía; Homofobia; Redes Sociales.

\section{Abstract}

he study is the result of the analysis of a post and its comments made in cyberspace, in the social network Facebook, given by a public figure of a political party in the municipality of Rio Grande - RS, about the gender discussions in the Human Sciences, specifically, in Geography. We present a reflection on the "unknown",

\footnotetext{
${ }^{1}$ Mestrando do Programa de Pós-graduação em Geografia - Universidade Federal do Rio Grande - Rio Grande / RS, Brasil. diego_rgnunes@yahoo.com.br
} 
assessing that in the disciplinary field of geographic science, studies of gender and sexualities have been discussed for more than 40 years. From the analysis of the publication, we pointed out that the post and its comments are marked by homophobic discourses and crossed by conservative looks and ignorance about what geographic science studies. We understand that gender studies in geography are powerful for an expanded view of geographic space, knowing that it is produced by subjects and their social markers. With this, we understand that addressing gender and sexuality studies in traditional areas is to give visibility to historically marginalized groups and thereby reduce socio-spatial inequalities.

Keywords: Conservatism; Gender; Geography; Homophobia; Social Networks

\section{Introdução}

Inicialmente se faz necessário explicar o título deste artigo, quando colocamos a palavra desconhecido entre aspas, estamos apontando que nesta situação da postagem na rede social Facebook e para aquelas pessoas que produziram tais discursos, os estudos de gênero na ciência geográfica podem não ser conhecidos. Neste sentido, este trabalho busca, entre tantos apontamentos, mostrar a relevância das temáticas de gênero no campo geográfico e apresentar as reflexões sobre os comentários produzidos por determinada postagem. Assim, nossa pretensão é dar visibilidade a estes estudos e também mostrar o quanto as redes sociais produzem efeito sem o menor conhecimento das pesquisas produzidas.

No dia 7 de maio de 2018, uma figura pública, vinculada a um partido político conservador do município do Rio Grande - RS, fez uma publicação a partir da vinculação de um convite para qualificação de mestrado em Geografia no site institucional da Universidade Federal do Rio Grande, com o seguinte título: "A produção das masculinidades e sócioespacialidades de homens que buscam parceiros do mesmo sexo no aplicativo Tinder no município do Rio Grande - RS”. A partir desta divulgação que a postagem foi realizada em seu perfil no Facebook, conforme figura 1.

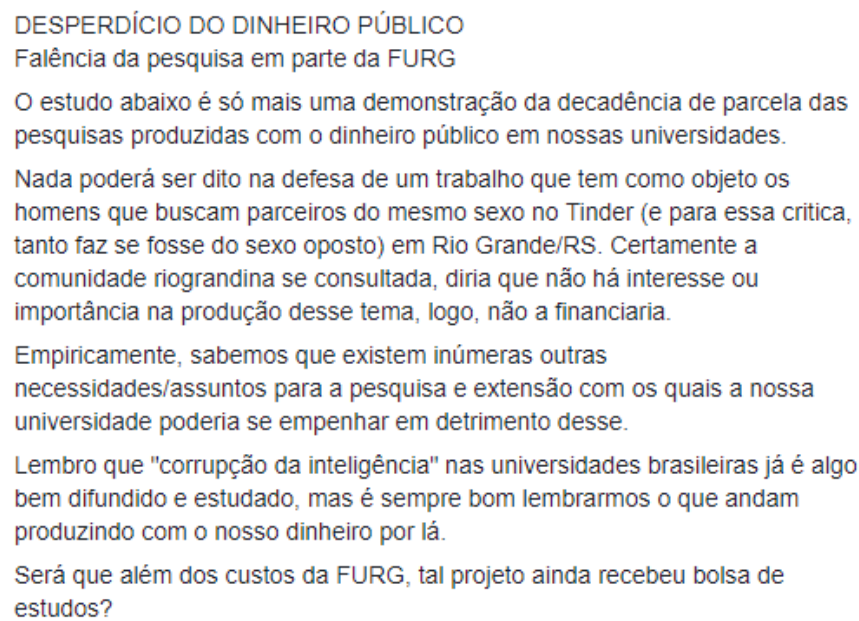

Figura 1: Postagem no Facebook.

Fonte: Perfil pessoal do autor da postagem na rede social Facebook. 
Assim, pelo conteúdo da postagem, temos indícios de que o autor da mesma desconhece as pesquisas da ciência geográfica, bem como afere, a partir da veiculação apenas do título, conclusões sobre o que é ou não ser pesquisa acadêmica. A postagem rendeu 328 comentários e 13 compartilhamentos. É necessário que façamos uma reflexão, sobre a publicação do Facebook e a dimensão que ela toma, a partir do contato em rede. Este, definido por Castells (2010) como a sociedade em rede, cada vez mais conectada na contemporaneidade.

As redes são caracterizadas por suas múltiplas formas e funções, criando arranjos relacionais comuns no século XXI. A todo momento, redes são produzidas, territórios são instituídos, a fim de garantir novas organizações sociais. As redes produzidas e construídas são definidas a partir de um conjunto de características, de acordo com os atores que a concebem e suas conexões. Os atores são as pessoas que constituem os primeiros elementos a serem considerados, aquelas capazes de moldar as estruturas sociais através do fortalecimento dos laços sociais. As conexões seriam formadas pela interação entre atores, o elo entre conexão e atores modifica e forma as estruturas sociais.

Compartilhando do pensamento de Bauman (2001), na modernidade líquida pensada por ele, é vital que os seres humanos interajam uns com os outros. E assim seria a vida em rede. Sobreviver a esse espaço é fazer parte do meio social. De fato, nos tornamos reféns de um mercado ávido por consumidores que, por sua vez, também são ávidos. É uma relação de troca ou de necessidade de ambos. "O mundo formado e sustentado pela sociedade de consumidores fica claramente dividido entre as coisas a serem escolhidas e os que escolhem; as mercadorias e seus consumidores: as coisas a serem consumidas e os seres humanos que as consomem" (BAUMAN, 2008, p. 20).

Bauman (2008) ressalta que deixamos o off-line para nos inserirmos em uma "cibervida" ou em uma vida "sem fio", cada vez mais plugada e com necessidades variadas. Para Sibilia (2008), tanto na internet quanto fora dela, somos atiçados pelo mercado do consumo, potencializando a criatividade de ser e estar nos espaços virtuais, o que fomenta o capitalismo contemporâneo.

Bauman (2008) salienta que, inserida nessa nova forma de interação, "a necessidade que a sociedade contemporânea tem em expor, dentro do universo das tecnologias, a sua vida pública é dar visibilidade ao invisível e ao mesmo tempo não ficar fora do 'mundo líquidomoderno dos consumidores" (BAUMAN, 2008, p. 09).

Para Sibilia (2008), a exposição é imperativa, incitada pela visibilidade em detrimento de novas formas de autoconstrução, por vezes, sociabilidades líquidas. Para a autora, 
a rede mundial de computadores se tornou um grande laboratório, um terreno propício para experimentar e criar novas subjetividades: em seus meandros nascem formas inovadoras de ser e estar no mundo, que por vezes parecem saudavelmente excêntricas e megalomaníacas, mas outras vezes (ou ao mesmo tempo) se atolam na pequenez mais rasa que se pode imaginar (SIBILIA, 2008, p. 27).

Com isso, Recuero (2010) aponta que redes sociais são laços criados dentro ou fora do espaço virtual e as mídias digitais, por sua vez, seriam o caminho para a criação das redes, incluindo a internet como um desses caminhos. Sendo assim, as redes sociais tem o objetivo de traçar uma conexão entre as pessoas, já as mídias possuem um significado mais amplo, constituída por meio da utilização de aparatos tecnológicos.

Os avanços criados pela era informacional deram sustentação a uma sociedade cada ver mais interconectada. Costa $(2005$, p. 236) afirma que "[...] a sociedade é fruto de uma árdua e constante negociação entre preferências individuais[...]”. E destaca que essa interconexão entre pessoas e meios virtuais “[...] implica que tenhamos de nos confrontar de algum modo, com nossas próprias preferências e sua relação com aquelas de outras pessoas" (p. 236). Essa capacidade de interação entre as pessoas e a habilidade de construção de redes de comunicações é classificada, segundo alguns autores/as como "capital social” (COSTA, 2005).

Neste sentido, a rede como arranjo social, passou a ser parte do cotidiano das pessoas, e muitas vezes utilizada como instrumento de ação política. Fazer check-in, marcar pessoas em fotos, realizar compras pela internet, ter diversos grupos sociais em espaços virtuais, possuir uma pluralidade de aplicativos, tudo isso são apenas alguns traços da sociedade contemporânea, cada vez mais plugada e sem fio. A tecnologia atravessou gerações, ligando desde as pessoas mais novas à terceira idade. Os nativos e/ou imigrantes digitais estão agora preocupados com seus smartphones, ainda de manhã já são acordados pelo alarme do celular, aproveitam para ver a temperatura e se atualizam das principais notícias do dia, antes mesmo de saírem da cama.

Existe uma frase, popularizada pelos/as internautas que é "se está no Facebook é verdade”. Entendemos assim, que a postagem é tendenciosa, em hipótese nenhuma é neutra e é compartilhada pelos seguidores do autor que a fez. Assim, este artigo irá buscar dar visibilidade aos estudos de gênero no campo geográfico e também apontar, a partir da análise de conteúdo, os comentários homofóbicos produzidos na postagem. Assim, dividimos o artigo em três momentos: Ciberespaço e cibercultura; Os estudos de gênero no campo geográfico; Análise do conteúdo da postagem. 


\title{
2. Ciberespaço e Cibercutura
}

Segundo Lévy (1999), não existe sociedade que não esteja dentro da cibercultura, a qual ele define como a cultura que emerge através da troca de informações pela rede mundial de computadores. A partir do século XX, como já mencionado no início deste capítulo, essa grande rede é marcada pelo aprimoramento das tecnologias digitais, construindo uma nova cultura contemporânea. De acordo com o autor, as dinâmicas informacionais e a interação entre o espaço físico e o virtual são constituintes da construção e da constituição do ciberespaço, definido como:

\begin{abstract}
O espaço de comunicação aberto pela interconexão mundial de computadores e das memórias dos computadores. Essa definição inclui o conjunto dos sistemas de comunicação eletrônicos (aí incluídos os conjuntos de redes hertzianas e telefônicas clássicas), na medida em que transmitem informações provenientes de fontes digitais ou destinadas à digitalização (LÉVY, 1999, p. 94-95).
\end{abstract}

Originalmente, a "palavra ciberespaço foi criada em 1984 por William Gibson em seu romance de ficção científica Neuromancer" (p. 94). Segundo Champangnatte e Cavalcanti (2015, p. 314), “o ciberespaço emerge como um território sem fronteiras, aparentemente sem controles e hierarquias, em que não há pontos fixos e nem lineares para a disseminação de informações".

Champangnatte e Cavalcanti salientam que

[...] os processos no ciberespaço sejam conduzidos por características que claramente se distinguem daquelas utilizadas pelos meios de comunicação tradicionais, compreende-se que existe uma relação de complementaridade entre ambos que resulta em ressonâncias e atravessamentos desses processos. Assim como o rádio não substituiu o jornal e também a TV não acabou com o rádio, não há nenhuma evidência de que a web vá ocupar o lugar de todas as mídias que a antecederam. É importante salientar que o novo território comunicacional, da internet, não elimina o poder e a capacidade dos meios massivos da indústria cultural, pois ambos os territórios coexistem e se atravessam. Desse modo, a passagem para um novo ambiente comunicacional pode permitir, mas não garante, a reconfiguração das formas de produção e da circulação de informação. O que pode promover tal reconfiguração são as novas possibilidades de criação e gestão de ambientes alternativos às grandes corporações midiáticas, a partir do ciberespaço (CHAMPANGNATTE E CAVALCANTI, 2015, p. 314).

Para os autores, a internet, mesmo como um dispositivo de interação e de grandes alcances, não se sobrepõe a outras culturas de massas, uma vez que em todos os meios comunicacionais encontraremos diferentes públicos, com distintos objetivos e atravessados por ideologias diversas. Com isso, o ciberespaço seria um território instituído pela interconexão virtual, o qual ainda oportuniza que se criem aquilo que Lévy (2003) vai chamar 
de inteligência coletiva - "uma inteligência distribuída por toda a parte, incessantemente valorizada, coordenada em tempo real, que resulta de uma mobilização efetiva das competências" (p. 28).

Retornamos à cibercultura de Lévy para compreender o processo de construção das novas sociedades. A emergência de uma cultura cibernética criaria cidades virtuais/virtualizadas? Segundo Lemos (2004, p. 09), "as cibercidades nascem no contexto das novas tecnologias da informação". A transformação acelerada dos meios tecnológicos deu início ao que esse autor denomina como cibercidade, sendo a cidade da cibercultura. Conforme explica Lemos (2004),

cibercidade nada mais é do que um conceito que visa colocar o acento sobre as formas de impacto das novas redes telemáticas no espaço urbano. Redes de cabos, fibras, antenas de células, espectro de ondas de rádio permitindo uma conexão wi-fi, entre outras, estão modificando a nossa vivência no espaço urbano através do teletrabalho, da escola on-line, das comunidades virtuais, dos fóruns temáticos planetários. O que está em jogo é a redefinição dos espaços públicos e do espaço privado (LEMOS, 2004, p. 20).

Todavia, devemos distanciar o fenômeno cibercidade de algo radical, na verdade, ela denota de uma reconfiguração do espaço urbano que está em constante transformação. Não se pauta por uma substituição do espaço físico pelo espaço virtual, mas sim na emergência de inteligências coletivas capazes de fortalecer laços comunitários (LEMOS, 2004). Para Lemos, "a ciência da inteligência coletiva busca apropriar o potencial agregador da rede para o exercício da cidadania" (p. 22).

Contudo, o que é, afinal, o virtual que tanto mencionamos? Quais as implicações e as contribuições desse espaço para a sociedade contemporânea? Focamos, a partir de agora, nesse conceito, por entender que ele atravessa tudo o que já foi discutido até o momento e o que virá a seguir. Segundo Lévy (1996, p. 15), “a palavra virtual vem do latim medieval virtualis, derivado por sua vez de virtus, força, potência”. Ainda, o autor trabalha com a ideia de que real e virtual não são opostos, sendo oposição daquilo que é atual: “[...] virtualidade e atualidade são apenas duas maneiras de ser diferentes" (LÉVY, 1996, p. 15). Para Alliez,

a relação do atual com o virtual constitui sempre um circuito, mas de duas maneiras: ora o atual remete a virtuais como a outras coisas em vastos circuitos, onde o virtual se atualiza, ora o atual remete ao virtual como a seu próprio virtual, nos menores circuitos onde o virtual cristaliza com o atual. O plano de imanência contém a um só tempo a atualização como relação do virtual com outros termos, e mesmo o atual como termo com o qual o virtual se intercambia. Em todos os casos, a relação do atual com o virtual não é a que se pode estabelecer entre dois atuais. Os atuais implicam indivíduos já constituídos, e determinações por pontos ordinários; ao 
passo que a relação entre o atual e o virtual forma uma individuação em ato ou uma singularização por pontos relevantes a serem determinados em cada caso (ALLIEZ, 1996, p. 55-56).

Alliez corrobora com Lévy ao afirmar que o espaço virtual se complementa ao atual, em formas de circuitos, porém de maneiras distintas. Ambos pretendem transmitir a compreensão de que o ciberespaço é algo estabelecido por características virtualizadas, a partir de processos de territorialização, reterritoralização e desterritorialização. Esses conceitos são importantes para o campo da Geografia, e nas ciências da comunicação se assemelham. Segundo Souza (1995, p. 80), “[...] o território é definido e delimitado por e a partir das relações de poder”. Não distante do território físico, materializado, temos o virtual, um espaço não concreto, mas concebido a partir de relações sociais e de dominação, habilidade e possibilidade.

A emergência do ciberespaço constituiu novas formas sociais de organização, criando laços afetivos de comunicação. Esses canais são capazes de construir territórios, como já mencionamos, e de reconfigurar novos espaços a partir de necessidades específicas. Para Miskolci (2017), “foi o encontro do PC (computer personal) com o telefone que possibilitou a disseminação da internet” (MISKOLCI, 2017, p. 20-21). A internet possibilitou uma maior interatividade entre as pessoas, oportunizando novos arranjos comunicacionais.

Para Recuero (2012), os novos arranjos da comunicação são fruto de um movimento social e temporal, oriundo de profundas modificações com o passar dos anos. Parafraseando a autora, as novas tecnologias oportunizam espaços de interação de indivíduos com outros indivíduos, "buscando estabeler e/ou manter laços sociais" (p. 16). De acordo com o pensamento da autora, esses espaços passam a serem vistos como espaços de lazer, agregados ao cotidiano das pessoas. Serão aí que "as práticas sociais começam a acontecer, seja por limitações do espaço físico, seja por limitações da vida moderna, seja apenas pela comodidade da interação sem face" (RECUERO, 2012, p. 17).

A sociedade em rede ou das redes se consolidou a partir da organização das estruturas informacionais e daquilo que Miskolci (2017) irá chamar de três grandes transformações articuladas, sendo elas: as transformações culturais e políticas deflagradas pelos movimentos sociais da década de 1960, como o feminista e, acrescentaria, o movimento homossexual; a revolução informacional instalada na década de 1970; e a reestruturação capitalista da década seguinte (MISKOLCI, 2017, p. 21). Segundo o autor, 
a vida conectada em rede começou a contestar a separação entre o on-line e o offline, assim como a de que seria possível viver em um espaço alternativo e com regras próprias. Não só as normas do velho cotidiano face a face moldam nossas relações on-line, mas também - desde que o acesso à rede se disseminou - as características das interações por mídia digitais têm passado a modificar as do dia a dia. Talvez até seja mais acurado aventar que vivemos em uma nova esfera relacional, cujos horizontes, regras e também limitações estamos descobrindo ao mesmo tempo em que nela adentramos (MISKOLCI, 2017, p. 22).

As mudanças no dia a dia são reflexos de novas formas de ser e estar na vida contemporânea. E é a partir dessas formas que construímos limitações e descontruímos barreiras, à medida que nos infiltramos nesse mundo da conectividade. Para Recuero (2012, p. 17), as "milhares de trocas entre as pessoas que se conhecem, que não se conhecem ou que se conhecerão representam conversações que permeiam, estabelecem e constroem as redes sociais" . Serão estas que estabelecerão a conversação em rede, que para a autora é definida como "uma nova forma conversacional, mais pública, mais coletiva" (p. 17).

Para Recuero (2012), o contemporâneo modelo de interação ${ }^{2}$ permite o delineamento da construção de redes, compreendendo sentimentos de determinados coletivos e obtendo informações sobre grupos que se organizam na rede e por ela. A potência das redes sociais é imensurável, a ponto de influenciar debates políticos e no planejamento e na prática de manifestações públicas.

Talvez a contestação da separação do on-line e off-line que Miskolci (2017) aponta seja bem exemplificada nas redes sociais, pois é algo intrínseco e presente nos atores sociais. O público e o privado se entrelaçam, e aquilo que está posto nas redes toma proporções e influências incalculáveis. Recuero (2012) afirma, nesse sentido, que as redes sociais não são "pré-construídas", mas sim moldadas pelas práticas dos atores que nela adentram. Para a autora,

contextos são convencionados pelos interagentes através de negociação. É uma conversação em rede, múltipla, espalhada, com a participação de muitos, e que permanece gerando novas apropriações e migrando entre as diversas ferramentas (RECUERO, 2012, p. 36).

Todavia, são as apropriações das redes sociais que nos fazem pensar nas diferentes formas de sociabilidade. Os processos de transformações ocorrem diariamente e a adaptação dos atores se dá devido a necessidades específicas, moldadas pelas ferramentas de interconexão. Ou seja, agenciamentos são constantemente construídos para a manutenção de redes ou a criação de novas formas de ser e estar no ciberespaço.

\footnotetext{
${ }^{2}$ Recuero (2012) utiliza os termos “interação" e conversação" como sinônimos.
} 
Um ponto importante a ser pensado sobre as redes sociais é a relação público versus privado. Até que ponto existem demarcações que garantem um certo conforto aos atores sociais, em detrimento da sua vida particular? A criação de qualquer perfil em uma rede, exige uma série de informações a serem preenchidas para que se possa estar nela. Uma vez completados os dados, o usuário passa a ter acesso àquilo que a ferramenta se propõe, à interatividade.

Para Recuero (2012), esse é o maior problema para o gerenciamento do que é público e do que é privado. Quando aceitamos alguém em nossas redes sociais, seja por qualquer motivação que somos impulsionados, estamos construindo nós, "conexões-pontes" ou "conexões fracas" (p. 148), para administrar aquilo que somos, postamos e falamos nas redes. Quando se aceita um "amigo" em determinada rede social, não existem fronteiras sobre as interconexões daquilo que foi dito em determinado espaço com aquilo compartilhado nos outros espaços.

Recentemente, em 2018, a maior rede social da internet, o Facebook, informou que pelo menos 87 milhões $^{3}$ de usuários/as tiveram seus dados vazados, a maioria pertencente aos Estados Unidos. Segundo informações da rede, os dados foram explorados de forma inapropriada pela Cambridge Analytica, empresa que prestou consultoria política na campanha do presidente dos EUA, Donald Trump.

O Facebook admitiu o erro na política de privacidade dos dados dos usuários e iniciou tentativas para corrigi-los. No entanto, o fundador da rede social afirma que houve um ruptura significativa na confiança dos usuários com a empresa. Ainda, divulgou o número estimado de usuários que foram afetados por países, o Brasil é o oitavo país, com pouco mais de 443 mil usuários com dados explorados.

Para Recuero (2012), as práticas de visibilidades precisam ser repensadas e negociadas com os demais atores que compõe a rede, por mais que elas estejam intrinsicamente ligadas a eles. Pensar que não existe segurança no ciberespaço é compreender como a sociedade contemporânea se comporta diante da insegurança. Indo mais além, é necessário entender que o privado se tornou público a partir do momento em que a própria sociedade organizada desenvolveu dispositivos que permitissem tal exposição.

\section{Os estudos de gênero no campo geográfico}

\footnotetext{
${ }^{3}$ Disponível em: < https://g1.globo.com/economia/tecnologia/noticia/facebook-eleva-para-87-milhoes-o-n-deusuarios-que-tiveram-dados-explorados-pela-cambridge-analytica.ghtml> Acesso em: 05/04/2018.
} 
Destacamos que a geografia humana, vem se dedicando a mais de 40 anos, com uma larga produção, a estudar as temáticas relacionadas ao gênero e sexualidades, compreendendo que o espaço ele é resultado produto de corpos que não são neutros, caracterizados por marcadores sociais (gênero, raça, etnia, cor, geração e etc) (SILVA e ORNAT, 2011). Segundo Veleda da Silva (2009) os movimentos feministas da década de 1970 foram importantes para a construção daquilo que chamamos hoje de Geografias Feministas, no plural, por compreender que existem diversas vertentes dentro deste mesmo campo.

Neste sentido, o viés feminista é importante para compreender não só a produção do espaço, mas também reduzir as desigualdades sócio-espaciais existentes, desconstruindo alguns pensamentos hegemônicos e visando uma sociedade mais igualitária. Segundo Veleda da Silva (2000) é ainda na década de 1970 que a geografia começa a trabalhar temas ligados a mulher, na perspectiva de gênero e trabalho. E as décadas de 1980 e 1990 se intensificou a incorporar os marcadores como sexualidades, gênero, raça e classe (SILVA, 2009).

Assim, o campo geográfico tem feito um grande esforço desde a década de 1970 para mostrar com pesquisas, que os estudos que envolvem os marcadores sociais são importantes para a sociedade, apesar de existir grande resistência conservadora por segmentos da nossa sociedade. Segundo Silva (2009. P. 60) ““"qualquer ciência que tenha como foco de análise as relações humanas deve ter em conta que a humanidade não é uniforme e que a diferença entre homens e mulheres é uma das principais categorias de análise." Os movimentos feministas atrelados ao movimento gay dos anos 1970 fomentam as discussões sobre as masculinidades. Quadrado (2012, p. 43) afirma que, "a partir desses movimentos, as políticas identitárias masculinas começaram a ser problematizadas, adotando-se o entendimento de que a dominação masculina se dava, também, sobre os homens, e não apenas sobre as mulheres"

Sobre estas discussões, Silva (2012) nos coloca a pensar sobre as masculinidades e tece que,

as vivências masculinas concretas são múltiplas e são indissociáveis das feminilidades. Há homens responsáveis pelos trabalhos domésticos, os que lutam pelo direito de cuidar dos filhos nos processos de separação, desempregados, gays, negros e muitos outros que não podem ser simplesmente classificados num papel universal de dominação em um modelo binário e linear de poder que produz a simplificação entre homem repressor / mulher subordinada (SILVA et. al., 2012, p. 137-138).

Diante do exposto, Silva nos coloca a pensar sobre a construção das masculinidades no campo da Geografia, que emerge a partir dos Estudos de Gênero na década de 1980, o qual foi denominado de Geografias Feministas. A autora propõe uma reflexão acerca do conceito de 
masculinidade, entendendo como constituinte do campo do gênero. Uma vez que aponta existirem diversas feminilidades, seria incoerente negar que existem a multiplicidade de masculinidades. Segundo Silva,

[...] é cabível que existam muitas masculinidades e não apenas a masculinidade do perfil hegemônico do homem branco, heterossexual, abastado e cristão. As diversas formas de vivência das masculinidades implica considerar a pluralidade de relações que homens estabelecem através das espacialidades (SILVA et. al., 2012, p. 142).

Silva nos coloca a pensar na subversão da ordem de um padrão normativo, a partir da “dissociação da relação direta entre sexo e gênero", pensando que os sujeitos podem expressar seu gênero de forma isolada do sexo. Com isso, "é possível viver masculinidades em corpos considerados femininos e/ou viver feminilidades em corpos considerados masculinos" (SILVA et. al., 2012, p. 143).

Ainda que os estudos do espaço e as masculinidades sejam incipientes na Geografia, como apontam Almeida e Ornat (2014), é importante a discussão na área, uma vez que já é “consolidada na produção geográfica anglofóna” (SILVA \& ORNAT, 2011). Pelo caráter inicial, "os estudos sobre múltiplas masculinidades constituem-se enquanto um desafio à Geografia Brasileira" (ALMEIDA \& ORNAT, 2014, p. 143). Costa (2011) vai ao encontro do pensamento de Almeida e Ornat quanto ao fazer geográfico, afirmando:

O que queremos argumentar é que as situações de interação é que conduzem à expressão diferenciada dos sujeitos quanto às suas identificações estéticas e de gênero, e isto é estabelecido como um acordo tácito entre performances de diferentes sujeitos em situação de interação. Isso é de fundamental teor geográfico, mas de uma geografia que deve se complexificar por análises situacionais de diferentes grupos focais (COSTA, 2011, p. 339).

O autor instiga a pensar a complexidade dos estudos sobre gênero para além do que já está dado, pensando a partir de uma Geografia "mais plural" com visões e entendimentos diversos. A Geografia, enquanto ciência, também deve se preocupar com as relações sócioespaciais dos gêneros, compreendendo, a partir dos diferentes lugares, territórios, espaços que os sujeitos se encontram na relação espaçotemporal. Problematizar a pensar as masculinidades ainda se constituem como um saber geográfico em construção, visto que são poucos os/as geógrafos/as que estudam tal temática, porém presente nos principais indexadores da área.

\section{Análise do conteúdo da postagem}

Com relação a análise da postagem e de seus comentários, trabalhamos com a Análise de Conteúdo (AC), a partir de Maria Franco (2008), Laurence Bardin (2009) e Roque 
Moraes (1999). Moraes define a técnica como "uma metodologia de pesquisa usada para descrever e interpretar o conteúdo de toda classe de documentos e textos" (p. 19).

Nos estudos/escritos de Bardin (2009), a Análise de Conteúdo é entendida como um método que representa um conjunto de técnicas para analisar diferentes dados oriundos de comunicações, utilizando-se de fases sistemáticas e objetivando realizar as descrições do conteúdo do material produzido. O mesmo autor afirma que "a análise do conteúdo é um conjunto de instrumentos de cunho metodológico em constante aperfeiçoamento, que se aplicam a discursos (conteúdos e continentes) extremamente diversificados" (BARDIN, 2009, p. 15).

Para Franco (2008), a Análise de Conteúdo possui como característica usos sobre a relação exposta na mensagem da comunicação (seja ela verbal, gestual, silenciosa, figurativa, documental). Segundo a autora, nessa relação, extraímos significados e sentidos que deverão, em algum momento, serem interpretados, no entanto, deve-se considerar as múltiplas condições dialógicas, percebendo sob um viés crítico e dinâmico da linguagem comunicativa expressa pelos participantes e considerando seus componentes cognitivos, afetivos, valorativos e ideológicos que irão conferir diferentes significados ao objeto da pesquisa. Essas questões dependerão da perspectiva teórica e atitudinal do pesquisador em relação à temática em estudo (FRANCO, 2008).

Moraes (1999) expõe que, de certo modo, "a análise de conteúdo é uma interpretação pessoal por parte do pesquisador com relação à percepção que tem dos dados. Não é possível uma leitura neutra" (p. 3). Segundo os autores citados, a Análise de Conteúdo possui algumas fases. Para Bardin (2009) e Franco (2008), ela se organiza em torno de três polos: 1. A préanálise; 2. A exploração do material; e, por fim, 3. O tratamento dos resultados: a inferência e a interpretação. Para Moraes (1999), o processo de análise divide-se em cinco fases: 1 Preparação das informações; 2 - Unitarização ou transformação do conteúdo em unidades; 3 Categorização ou classificação das unidades em categorias; 4 - Descrição; 5 - Interpretação.

Assim, buscamos pontos de convergência e divergência nos comentários da postagem e conseguimos transformar em unidades para análise, sendo elas: moral; relevância social; aparelhamento; procurando homens; desperdício de dinheiro; Cyberbullying. Neste sentido, entendemos num primeiro momento que a postagem foi realizada em um contexto político específico, assim, os seguidores da mesma postagem são ligados ao mesmo viés ideológico do autor da mesma.

Quando mencionam a palavra moral, sempre atrelam o título da pesquisa em questão a uma subversão do que a ciência geográfica, no ponto de vista deles, estuda. Assim, a partir 
apenas do título, eles julgam que a pesquisa fere a moral e os bons costumes, não existindo importância em pesquisar tal temática. Outro ponto levantado pelos comentários foi o aparelhamento das instituições, a todo momento esta palavra está presente nas narrativas, compreendo que o contexto político faz com que eles acreditar existir um aparelhamento das estruturas públicas nos governos do Partido dos Trabalhadores.

Ao longo dos comentários, mais de um seguidor comenta que o pesquisador está se utilizando da pesquisa para procurar homens, num sentido pejorativo, desqualificando a relevância social do estudo sem ao mesmo ter contato com o conteúdo, assim atrelado a um suposto desperdício de dinheiro público. Por fim, uma das pessoas que comentam na postagem defende a pesquisa, apontando que ali estava existindo um cyberbullying e era justificável uma ação judicial por exposição dos pesquisadores.

O que podemos concluir da postagem e de seus comentários, a Universidade Federal do Rio Grande vem sendo alvo de olhares dos conservadores quando a temática está atrelada à discussão de gênero. Assim, a postagem em si reflete o viés ideológico, mais para frente seu pai seria candidato a deputado federal, assim entendemos o interesse em buscar agredir a instituição. Existe um desconhecimento sobre o que a geografia estuda, e isso é algo que não está posto como a geografia econômica, política e agrária. Por mais consolidado que seja os estudos de gênero no campo geográfico é preciso que pesquisadores/as destas temáticas saiam de suas caixinhas e mostrem seus estudos em outros espaços.

Outro ponto que podemos considerar relevante é o preconceito por trás da postagem e de seus comentários, o autor não quis apontar que era apenas desperdício de dinheiro público, pelo contrário, ele quis mostrar que era um homem pesquisando homens que buscavam parceiros do mesmo sexo num aplicativo de relacionamento. Assim, isso vai de encontro ao que ele entende como certo ou errado. No entanto, entendemos que os estudos de gênero na Geografia são potentes para uma visão ampliada do espaço geográfico, sabendo que este é produzido por sujeitos e seus marcadores sociais. Com isso, compreendemos que abordar os estudos de gênero e sexualidades em áreas tradicionais é dar visibilidade a grupos, historicamente marginalizados e, com isso, reduzir as desigualdades sócioespaciais.

\section{Referências}

ALLIEZ. Éric. Deleuze filosofia virtual. São Paulo: Ed. 34, 1996.

ALMEIDA, João Paulo Leandro de. ORNAT, Marcio José. Espacialidade e masculinidade na vivência de jovens da escola de 'guardas mirins' em Ponta Grossa, Paraná. Geo UERJ, v. 2, n. 
25, 2014. pp. $142-$ 171. Disponível em: < http://www.epublicacoes.uerj.br/index.php/geouerj/article/view/9553/10982> Acesso em: 23/11/2017.

BARDIN, L. Análise de conteúdo. Lisboa: Edições 70, 2009.

BAUMAN, Zygmunt. Vida para consumo: A transformação das pessoas em mercadorias. Rio de Janeiro: Zahar, 2008.

BAUMAN, Zygmunt. Modernidade Líquida. Rio de Janeiro: Jorge Zahar Ed., 2001.

CASTELLS, Manuel. A sociedade em rede. São Paulo: Paz e Terra, 2010.

CHAMPANGNATTE, Dostoiewski Mariatt de Oliveira. CAVALCANTI, Marcus Alexandre de Pádua Cibercultura - perspectivas conceituais, abordagens alternativas de comunicação e movimentos sociais. Revista de Estudos da Comunicação, Curitiba. v. 16, n. 41, p. 312 - 326. Set/ Dez. 2015.2 Disponível em: $<$ http://www2.pucpr.br/reol/pb/index.php/comunicacao?dd1=15877\&dd99=view\&dd98=p b> Acesso em: 03/09/2017.

COSTA, Benhur Pinós da; Geografias, masculinidades e homoerotismo: teorias, práticas e posicionalidades da pesquisa. In: SILVA, Joseli Maria; ORNAT, Márcio José; CHIMIN JUNIOR, Alides Babtista. Espaço, gênero \& masculinidades plurais. Ponta Grossa:Todapalavra, 2011, pp. $329-356$

COSTA, Rogério da. Por um novo conceito de comunidade: redes sociais, comunidades pessoais, inteligência coletiva . Revista Interface - Comunicação, Saúde, Educação, Botucatu. v. 09, n. 17, p. 235 - 248. Mar/ Ago. 2005. Disponível em: < http://www.scielo.br/scielo.php?script=sci_abstract\&pid=S1414-

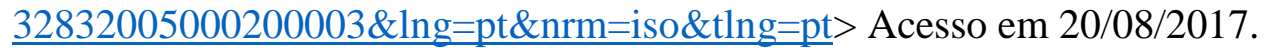

LEMOS, André. Cibercidade: A cidade na Cibercultura. Rio de Janeiro: E-Papers Serviços Editoriais, 2004.

FRANCO, M. L. P. B. Análise de Conteúdo/ Maria Laura Puglisi Barbosa Franco. - Brasília, $3^{\mathrm{a}}$ edição: Liber Livro Editora, 2008

LÉVY, Pierre. A inteligência coletiva: por uma antropologia do ciberespaço. 4.ed. São Paulo: Loyola, 2003.

LÉVY, Pierre. Cibercultura. São Paulo: Ed. 34, 1999.

LÉVY, Pierre. O Que é Virtual? Rio: Editora 34. 1996.

MISKOLCI, Richard. Desejos Digitais: Uma análise sociológica da busca por parceiros online. Belo Horizonte: Autêntica, 2017.

MORAES, R. Análise de conteúdo. Revista Educação, Porto Alegre, v. 22, n. 37, pp. 7-32, 1999. 
QUADRADO, Raquel. PRÁTICAS BIOASCÉTICAS CONTEMPORÂNEAS: notas sobre os corpos masculinos nas comunidades que discutem cirurgia plástica na rede social Orkut. 2012. Tese (Doutorado em Educação em Ciências) - Instituto de Educação, Universidade Federal do Rio Grande - FURG, Rio Grande, 2012.

RECUERO, Raquel. A conversação em Rede. Comunicação Mediada pelo Computador e Redes Sociais na Internet. Porto Alegre: Sulina, 2012.

RECUERO, Raquel. Redes sociais na internet. Porto Alegre: Sulina, 2010.

SILVA, Joselli Maria. ROSSI, Rodrigo. CHIMIN JUNIOR, Alides Baptista. ORNAT, Marcio Jose. Espaço, masculinidades e adolescentes em conflito com a lei. Geo UERG, v. 1, n.23. Rio de Janeiro, 2012, pp. 136 - 166. Disponível em: < http://www.epublicacoes.uerj.br/index.php/geouerj/article/view/370> Acesso em: 23/11/2017.

SILVA, Joseli Maria; ORNAT, Marcio Jose. Espaço e múltiplas masculinidades: um desafio para o conhecimento científico geográfico brasileiro. In: SILVA, Joseli Maria; ORNAT, Márcio José; CHIMIN JUNIOR, Alides Babtista. Espaço, gênero \& masculinidades plurais. Ponta Grossa:Todapalavra, 2011, pp. 23 - 54.

SOUZA, Marcelo José Lopes de. O território: sobre espaço e poder, autonomia e desenvolvimento. In: Geografia conceitos e temas/ Iná Elias de Castro [Org.]. - 2. ed. Rio de Janeiro: Bertrand Brasil, 1995. pp. 77 - 116.

SIBILIA, Paula. O show do eu: a intimidade como espetáculo, Rio de Janeiro: Nova Fronteira, 2008.

SILVA, J. M. Ausências e silêncios do discurso geográfico brasileiro: uma crítica feminista à geografia eurocêntrica. Geografias subversivas: discursos sobre espaço, gênero e sexualidades. SILVA, Joseli Maria (org). Ponta Grossa, PR : Todapalavra, 2009, 318p.

VELEDA DA SILVA, S. A perspectiva feminista na geografia brasileira. In: Geografias subversivas: discursos sobre espaço, gênero e sexualidades. SILVA, Joseli Maria (org). Ponta Grossa, PR : Todapalavra, 2009, 318p.

VELEDA DA SILVA, S. Os estudos de gênero no Brasil: algumas considerações. Biblio 3W. Revista Bibliográfica de Geografía y Ciencias Sociales, Universidade de Barcelona; nº 262,13 p., 2000. 